\title{
HIV testing within general practices in Europe: a mixed-methods systematic review
}

\author{
Jessika Deblonde ${ }^{1 *}$ D, Dominique Van Beckhoven', Jasna Loos ${ }^{3}$, Nicole Boffin², André Sasse', \\ Christiana Nöstlinger ${ }^{3,4}$, Virginie Supervie ${ }^{5}$ and HERMETIC Study Group
}

\begin{abstract}
Background: Late diagnosis of HIV infection remains a key challenge in Europe. It is acknowledged that general practitioners (GPs) may contribute greatly to early case finding, yet there is evidence that many diagnostic opportunities are being missed. To further promote HIV testing in primary care and to increase the utility of available research, the existing evidence has been synthesised in a systematic review adhering to the PRISMA guidelines.

Methods: The databases PubMed, Scopus and Embase were searched for the period 2006-2017. Two authors judged independently on the eligibility of studies. Through a mixed-methods systematic review of 29 studies, we provide a description of HIV testing in general practices in Europe, including barriers and facilitators.

Results: The findings of the study show that although various approaches to target patients are used by GPs, most tests are still carried out based on the patient's request. Several barriers obstruct HIV testing in general practice. Included are a lack of communication skills on sexual health, lack of knowledge about HIV testing recommendations and epidemic specificities, difficulties with using the complete list of clinical HIV indicator diseases and lack of experience in delivering and communicating test results. The findings also suggest that the provision of specific training, practical tools and promotion programmes has an impact on the testing performance of GPs.

Conclusions: GPs could have an increased role in provider-initiated HIV-testing for early case finding. To achieve this objective, solutions to the reported barriers should be identified and testing criteria adapted to primary healthcare defined. Providing guidance and training to better identify priority groups for HIV testing, as well as information on the HIV epidemic's characteristics, will be fundamental to increasing awareness and testing by GPs.
\end{abstract}

Keywords: HIV, HIV testing, Primary care, General practitioner, Europe

\section{Background}

From a clinical and public health perspective, early HIV care and treatment are associated with viral suppression, improved health outcomes and reductions in transmission risks [1-3]. However, due to significant barriers to HIV testing, many people living with HIV are diagnosed late in the course of the disease [4]. In Europe, Mocroft et al. [5] showed that although late presentation for HIV care has decreased over time, it remains a significant

\footnotetext{
* Correspondence: Jessika.deblonde@sciensano.be

${ }^{1}$ Sciensano, Epidemiology of Infectious Diseases, Juliette Wytsmanstraat 14, 1050 Brussels, Belgium

Full list of author information is available at the end of the article
}

issue in all HIV exposure groups. Over the 2000-2011 period, more than $50 \%$ of HIV-infected people were diagnosed late (defined as diagnosis with a CD4 count below 350 cells $/ \mu \mathrm{L}$ or an AIDS diagnosis in the first 6 months after diagnosis) and a third presented very late (defined as diagnosis with a CD4 count below 200 cells/ $\mu \mathrm{L})$. A recent update demonstrated no overall change in the proportion of late presentation since 2010 [6].

At the population level, late diagnosis drives the existence of a hidden epidemic, with a number of HIV-infected individuals remaining unaware of their HIV status for a considerable time before diagnosis [7]. HIV-infected people who are unaware of living with HIV

(c) The Author(s). 2018 Open Access This article is distributed under the terms of the Creative Commons Attribution 4.0 International License (http://creativecommons.org/licenses/by/4.0/), which permits unrestricted use, distribution, and reproduction in any medium, provided you give appropriate credit to the original author(s) and the source, provide a link to the Creative Commons license, and indicate if changes were made. The Creative Commons Public Domain Dedication waiver (http://creativecommons.org/publicdomain/zero/1.0/) applies to the data made available in this article, unless otherwise stated. 
cannot benefit from highly effective treatment and may unwillingly contribute to the on-going transmission of HIV infection [8]. In 2016, an estimated 101,400 people were living with undiagnosed HIV in the European Union/European Economic Area (EU/EEA) and the rate of new infections was 3.6 per 100,000 population. Despite the positive trend in reduced numbers of undiagnosed HIV infections in recent years, the median time from HIV infection to diagnosis was estimated at 2.9 years in 2016 [9].

Early diagnosis with prompt link to care and treatment therefore remains a priority in the fight against the HIV epidemic [10]. It is acknowledged that general practitioners (GPs) have a pivotal role in HIV testing for early case finding [11-15]. GPs are the main entry point into the health care system for a variety of health issues, including HIV. Moreover the long-term and holistic patient-doctor relationship provided by primary care services lends itself to the provision of personalised sexual health information and repeated testing opportunities [16]. However, several studies have shown that HIV-infected individuals who are diagnosed late, often have a history of missed opportunities for an earlier diagnosis, including multiple visits to primary care services $[17,18]$.

To further promote HIV testing in primary care settings, to design new interventions and to increase the utility of the available research, the existing evidence should be synthesised and diffused. To that end, we conducted a mixed-methods systematic review aimed at the integration of results from both qualitative and quantitative studies on this topic [19]. The research synthesis was guided by the following research question: what are the current practices of HIV testing in primary care settings in Europe, exploring the process from targeting patients to performing the test and results communication, identifying also the barriers and facilitators.

\section{Methods}

Mixed methods research, the paradigm that encourages the combined use of qualitative and quantitative research techniques, can be applied at the primary empirical study level as well as at the synthesis level. In such a synthesis, the data to be included in the review are findings extracted from qualitative, quantitative, and mixed methods primary level studies [20]. As the findings of various types of research dedicated to the present topic can be viewed as confirming and extending each other, an integrative mixed research synthesis as proposed by Sandelowski et al. [19] has been used. This mixed-methods systematic review was performed in accordance with the Preferred Reporting Items for Systematic Reviews and Meta-analysis (PRISMA) guidelines [21] (see Additional file 1).

\section{Search strategy}

In May 2017, the databases PubMed, Scopus and Embase were searched for studies on HIV testing in general practices in Europe. We applied a free text strategy and $\mathrm{MeSH}$ terms to systematically scan the databases. In order to ensure a comprehensive search, we employed a combination of broad search terms at the level of the title and abstract. The search terms "HIV testing" and "HIV screening" were combined using the Boolean and proximity operator OR. Also the terms "general practitioners", "general practice", "primary care", "family practice", "family practitioners" were combined with OR. The terms of both areas were merged with AND. The search strategy that we used in PubMed is given in Additional file 2; this search strategy was adapted accordingly for the Scopus and the Embase databases.

\section{Inclusion and exclusion criteria}

To be eligible, articles needed to be published in English between 2006 and 2017 in a peer reviewed journal, and report on empirical studies regarding HIV testing in general practice settings in Europe, taking into consideration at least one of the following aspects of HIV testing: sexual history taking, targeting patients, test proposal, performance, barriers and facilitators. We looked for peer-reviewed articles published from 2006 onwards as 2006 was the year in which guidelines for provider-initiated HIV testing were first released [22]. Conference proceedings, editorials and opinion papers were excluded from the review. Articles reporting on HIV testing in multiple settings without referring specifically to results for general practices, in community based settings (outreach) and on the effectiveness of indicator-disease-based testing if not specifically referring to HIV testing attitudes and practices of GPs, were also excluded.

General practice settings were defined as places where first-contact, non-specialised, long-term personfocused and comprehensive care for most health problems is provided by a physician in a sustained partnership with patients and in the context of family and community [23].

\section{Study selection}

The search for studies was done separately in each database. The study selection followed a two-step process: review of titles and keywords followed by an abstract review. Two of the authors independently screened all identified study titles. After removal of the duplicates, results from this screening were compared and those not deemed relevant were disregarded. Abstracts from selected studies were then assessed by both authors using the above eligibility criteria. The selected abstracts from the three databases were assembled and full text 
reports of selected studies were subsequently analysed and checked again for eligibility by both authors. The reference lists of the papers retrieved from the search in the databases were reviewed for additional relevant references using the same eligibility criteria.

\section{Quality appraisal}

One single checklist, adapted from Fakoya et al. [24, 25], was devised to assess the quality of both the selected quantitative and qualitative studies. Studies were given a quality score which incorporated a number of factors drawn from the PRISMA [21] and NICE guidelines [26] including the definition of a research question, description of the results, internal and external validity (see Additional file 3). For the quality appraisal of the qualitative studies we adapted the criteria from the checklist developed by Fakoya et al. [25] based on generally accepted criteria of scientific rigor in qualitative research [27]. Since qualitative research follows different research paradigms than quantitative research, we developed parallel items reflecting methodological soundness in qualitative research. To assess external validity, we used the concept of transferability, i.e. results can be applied to other similar populations and settings, which requires a sufficient description of the context in which the research was conducted. To assess the quality of outcome measures, we used the quality criteria of confirmability, i.e. research findings are supported by internally coherent data, including a transparent and systematic approach to data analysis such as triangulation, multiple coders, reflexivity, inclusion of discrepant results. Studies were rated within the paradigm of their study type and were graded as having an overall quality score of 'high', 'moderate', or 'low'. The quality assessment was carried out by two of the authors. Studies that received a 'low' score from both authors were excluded from the review.

\section{Data synthesis}

We performed a mixed research synthesis making use of an integrated design [9], in which studies are grouped for synthesis not by methods (i.e., qualitative and quantitative), but rather by findings perceived as addressing the same aspects of the study subject. The analytic emphasis is on transforming findings to combine them.

In this view, findings were categorised based on different aspects of the HIV testing practice namely trends of HIV testing, targeting of patients, test performance, as well as barriers and facilitators to HIV testing.

\section{Results}

Using the predefined search terms, 2296 potential manuscripts were identified in the three databases together (see for more information Fig. 1). After a first removal of duplicates, initial review for relevance based on title and availability of abstract, 183 abstracts remained to be screened for eligibility. After screening these abstracts, 110 articles were selected of which 44 articles were retrieved for full text analysis using the inclusion criteria. Three additional papers were found by checking the citations in the selected articles. In total 30 articles met the eligibility criteria. Based on the quality assessment, 29 studies were rated to have a high or moderate score. One mixed method study was rated with a low score as it did not provide sufficient information concerning the criteria of confirmability and transferability.

Twenty three quantitative studies were included, five qualitative studies and one had both a quantitative and qualitative approach. The studies were conducted in the United Kingdom (UK) $(n=9)$, France $(n=6)$, the Netherlands $(n=6)$, Belgium $(n=5)$ and Spain $(n=3)$. A few studies were done in multiple settings, including general practice. In these cases, only the results regarding HIV testing in general practice settings were singled out. Some studies dealt with one aspect of the HIV testing practice whilst others examined various topics.

\section{Trends in HIV testing}

Little is known about trends in HIV testing in general practice. A retrospective cohort study between 1995 and 2005 in the UK showed that HIV testing rates in primary care increased slowly but remained low at 71.3 and 61.1 tests per 100,000 persons year for males and females respectively [28]. A Dutch time-trend analysis comprising a 22-years period revealed a significant increase in HIV-related consultations from 7 per 10,000 registered patients in 1988 to 13 per 10,000 patients in 2009. An analysis of the number of HIV tests demonstrated an increase from $53 \%$ of patients being tested in 1988 to $88 \%$ in 2009. There was, however, a wide variation between general practices, with HIV tests being more often requested and performed in urban areas compared with rural areas [29]. A UK study making use of chlamydia and HIV testing data from general practices indicated substantial differences in the intensity of testing. Practices that tested more tended to have younger GPs who were more likely to have had education about sexually transmitted infections (STI) and HIV in their vocational training. As a consequence, they felt more comfortable discussing sexual health issues [30]. (See Table 1 for more information).

\section{Targeting patients}

Targeting patients for HIV testing requires awareness about their HIV risk. A Belgian qualitative study showed that GPs were not inclined to routinely collect and record sexual health information from their patients. Sexual behaviour was hardly ever discussed except in cases of genital complaint. Instead, assumptions about HIV risk 


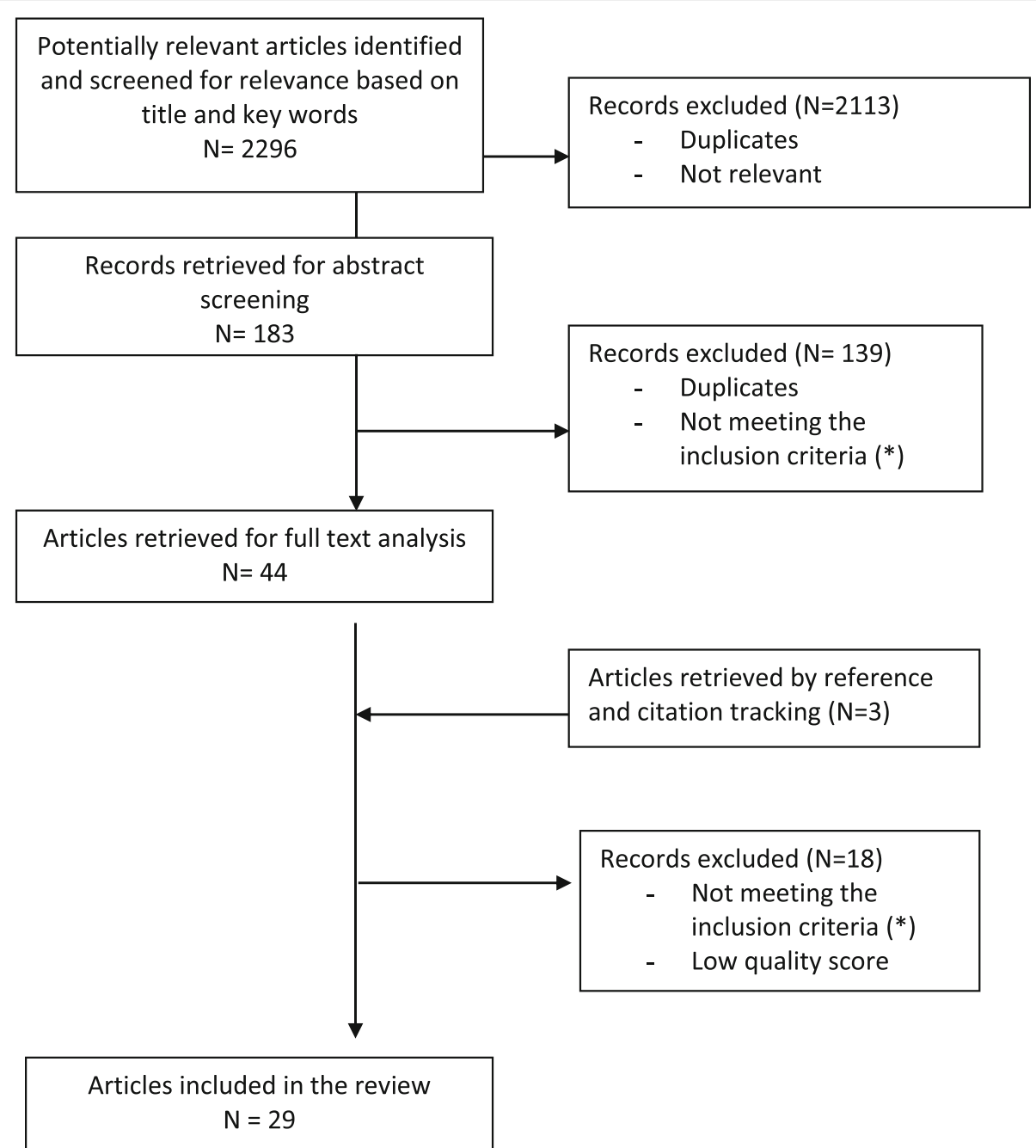

Fig. 1 Flow diagram of the article selection process. $\left(^{*}\right)$ Conference proceedings, editorials, opinion papers; studies conducted outside Europe; published in other languages than English; published in journals without peer-review; published before 2006; reporting on HIV testing in other settings; reporting on HIV testing in multiple settings without singling out results for general practices; reporting on HIV testing provided by general practitioners in community based settings (outreach); reporting on the effectiveness of indicator-disease-based testing if not referring specifically to HIV testing attitudes and practices of GPS

were based on certain patient characteristics such as country of origin, past STI episodes and sexual orientation [31]. A cross-sectional survey among newly diagnosed HIV patients $(N=111)$ in Amsterdam (Netherlands) revealed that sexual orientation was registered in the patients' record in $34 \%$ of the men having sex with men (MSM) cases. Information about the patient origins in HIV endemic countries was collected for $56 \%$ of the patients in the migrant group [32]. In the Belgian network of Sentinel General Practices, sexual history reporting was incomplete for $55 \%$ of the STI episodes recorded between 2013 and 2014, particularly in terms of number of partners and condom use [11].

With a view to better targeting patients for an HIV test in healthcare settings, multiple guidelines and recommendations have been developed. For example, the British HIV Association, the British Association of Sexual Health and HIV and the British Infection Society introduced joint guidelines in 2008 with specific criteria applicable to general practice [33]. A questionnaire survey conducted in 2012 among GPs $(N=80)$ from both low and high HIV prevalence areas in the UK showed, however, that about half of them were unaware of these guidelines; another third was aware of the existence of the guidelines but had never read them [34]. A similar study among GPs in Paris, France $(N=407)$ revealed that only $45 \%$ of them were aware of the national recommendations for HIV screening in general practice [35].

Different approaches to target patients for testing were examined. A few studies addressed the provision of routine HIV testing to all patients. It was perceived as a 
Table 1 Studies included in the review that report on trends in HIV testing

\begin{tabular}{|c|c|c|c|c|}
\hline Author, year & Country & Study design & Study population & Main findings \\
\hline Donker, 2013 [29] & Netherlands & $\begin{array}{l}\text { Retrospective cohort study } \\
\text { within the Dutch sentinel } \\
\text { general practice network, } \\
\text { 1988-2009 }\end{array}$ & $\begin{array}{l}56 \mathrm{GPs}^{\mathrm{a}} \text { in } 42 \text { general } \\
\text { practices }\end{array}$ & $\begin{array}{l}\text { Increase from } 53 \% \text { of patients } \\
\text { consulting for HIV and being } \\
\text { tested in } 1988 \text { to } 88 \% \text { in } \\
2009 .\end{array}$ \\
\hline Evans, 2009 [28] & UK & $\begin{array}{l}\text { Retrospective cohort study of } \\
\text { all general practices } \\
\text { contributing data to the UK } \\
\text { General Practice Research } \\
\text { Database, 1995-2005 }\end{array}$ & $\begin{array}{l}13.8 \text { million person years of } \\
\text { observation for males and } \\
13.9 \text { million person years for } \\
\text { females }\end{array}$ & $\begin{array}{l}11 \text {-fold increase in male } \\
\text { testing and 19-fold increase } \\
\text { in non-pregnant female } \\
\text { testing between } 1995 \text { and } \\
2005 \text {. } \\
\text { HIV testing rates in 2005: } 71.3 \\
\text { and } 61.2 \text { tests per 100,000 } \\
\text { person years for males and } \\
\text { females respectively. }\end{array}$ \\
\hline Sadler, 2010 [30] & UK & $\begin{array}{l}\text { Cross-sectional study using } \\
\text { laboratory data from primary } \\
\text { care settings in Brent and } \\
\text { Avon, 2003-2006 }\end{array}$ & 207 general practices & $\begin{array}{l}\text { Mean yearly HIV testing rate: } \\
0.6 \text { per } 1000 \text { patients aged } \\
15-44 \text { years in Brent and } 10.3 \\
\text { in Avon. } \\
\text { GPs in practices that tested } \\
\text { for HIV were younger: mean } \\
\text { age } 50.1 \text { years versus } \\
54.5 \text { years. }\end{array}$ \\
\hline
\end{tabular}

${ }^{\mathrm{a}} G P s$ general practitioners

way to reduce HIV-related stigma [36]. Two studies in France $(N=352 ; N=78)$ and another in the UK $(N=144)$ reported that a majority of GPs were favourable to implement routine testing [37-39]. Nevertheless, a study among GPs in the Pays de Loire (France) $(N=871)$ indicated that routine screening of all patients was not a standard practice [40]. Instead HIV testing was offered to populations at high risk for HIV acquisition, including people who inject drugs, sex workers, MSM and people coming from high HIV endemic countries [37, 40].

The guidance released by the HIV in Europe Initiative in 2012 recommends the provision of HIV testing for patients presenting with indicator diseases, defined as co-morbid diseases afflicting HIV infected persons disproportionally [41]. GPs in the Netherlands $(N=81)$ considered that the list of HIV indicator diseases as too long and not applicable in its current form in primary care [42]. In a survey among GPs in the UK $(N=80)$, the majority indicated that it would be feasible to routinely offer HIV testing to patients with the following HIV indicator diseases: STIs and multidermatomal or recurrent herpes zoster infection. Marked variation was seen, however, in attitudes towards testing in patients presenting with other clinical HIV indicator diseases [34]. Regarding the implementation of indicator-condition-guided HIV testing, two Spanish studies revealed that testing based on selected indicator conditions commonly seen in primary care settings was a feasible and efficient strategy to improve diagnosis of HIV infection [43, 44]. HIV testing, however, was only performed in a minority of cases, with the highest testing rates when the indicator condition episode included an STI [43].
Offering an HIV test during STI consultations was examined in more detail in a few observational studies. A first study implemented between 2008 and 2011 in the Dutch sentinel GPs network showed that HIV tests were not carried out for $64 \%$ of the STI-related consultations involving patients at higher risk for HIV, and in a more recent study in the same setting for $34 \%[45,46]$. In particular, MSM and persons originating from HIV-endemic countries were frequently not tested. The main reasons for not testing for HIV were that the GP considered that the individual risk for HIV infection was low or that the patient did not want to be tested or to discuss the topic of HIV during the STI consultation [45]. In the Belgian network of Sentinel General Practices, $23 \%$ of the STI patients never had an HIV test prior to the present STI [11]. A search in the electronic general practice database from 747 GPs in Rotterdam (Netherlands) revealed that for $32 \%$ of persons diagnosed with syphilis, no HIV test was reported. For gonorrhoea this was $45 \%$, for chlamydia $54 \%$ and for hepatitis B 61\% [47] (see Table 2 for more information).

\section{How the HIV test is performed}

Offering an HIV test without a patient's specific request, an immediate diagnostic need, or outside of 'a window of opportunity' such as a blood test for other clinical indications or a sexual or reproductive health consultation caused feelings of discomfort among GPs, who expressed concern with regard to the patient's potential reaction $[42,48,49]$. Therefore, HIV testing practices were generally limited to the above-mentioned situations [29, 32, 35-37, 40, 49]. However, this observation is not applicable to all 
Table 2 Studies included in the review that report on targeting patients

\begin{tabular}{|c|c|c|c|}
\hline Author, year & Country & Study design & Study population \\
\hline Agusti, 2016 [43] & Spain & $\begin{array}{l}\text { Retrospective observational } \\
\text { study making use of data } \\
\text { from a population-based } \\
\text { public health database, } \\
\text { 2010-2012 }\end{array}$ & $\begin{array}{l}99,426 \text { patients diagnosed } \\
\text { with an IC in primary care } \\
(N=102,647 \text { diagnosed ICs) }\end{array}$ \\
\hline Boffin, 2017 [11] & Belgium & $\begin{array}{l}\text { Retrospective observational } \\
\text { study making use of data } \\
\text { from the Belgian Network of } \\
\text { Sentinel General Practices, } \\
\text { 2013-2014 }\end{array}$ & $\begin{array}{l}306 \text { new STI }{ }^{\text {b episodes from }} \\
298 \text { patients, reported by } 83 \\
\text { of } 140 \text { sentinel practices } \\
\text { [no STIs were reported by } 5 \\
\text { practices]. }\end{array}$ \\
\hline
\end{tabular}

Fraisse, 2015 [37] $\quad$ France Cross-sectional questionnaire survey, 2013

Hall, $2015[40]$

France

Cross-sectional questionnaire survey among family physicians in the Pays de la Loire, 2011-2012

Hindocha, 2013 [34]

UK survey, 2012

Joore, $2017[32]$

Netherlands

Cross-sectional questionnaire survey among newly diagnosed HIV infected patients presenting at 2 HIV outpatient clinics in Amsterdam, 2014-2016

Joore, 2016 [42]

Netherlands

Qualitative study with FGDs and in depth-interviews, 2014

Joore, 2016 [45]

Netherlands
Retrospective observational study making use of a consultation-based data set from the Sentinel Practices of the Primary Care Database, 2008-2013, combined with a questionnaire survey among GPS
$78 \mathrm{GPs}^{\mathrm{c}}$ working in a $150,000-$ population district in the south of France

871 GPS

80 GPs from areas of high and low HIV prevalence

111 newly diagnosed HIV patients

6 FGDs ${ }^{f}$ including 81 GPs and in- depth interviews with 9 key-informants

907 STI-related consultations in high risk groups
Main findings

An HIV test was performed within 4 months in 18,515 of the episodes in which an IC was diagnosed (18,5\%).

For $54.6 \%$ of all STI episodes an incomplete sexual history was reported: the highest proportion of missing values was found for the number of sex partners in the past 6 months (37.6\%) and condom use (25.2\%).

One in three STI patients (33.1\%) had never been tested for HIV. Excluding those episodes for which an HIV test was planned, 23.3\% never had a test (planned).

For high risk populations, including PWID, sex workers, $\mathrm{MSM}^{\mathrm{e}}$ and people coming from high endemic countries, $61 \%$ of the GPs proposed HIV testing once a year.

Routine screening of all patients was not a standard practice. $72.5 \%$ of GPs offered an HIV test to pregnant women; $70.2 \%$ to patient engaging in unsafe sex; $38.6 \%$ to MSM; $19.9 \%$ to patients presenting with symptoms of HIV and 12.5\% to patients of African origin.

$44 \%$ of GPs were unaware of national HIV testing recommendations.

$88 \%$ would routinely test STI patients; $4 \%$ would routinely test all patients with one of the $10 \mathrm{ICs}$ considered most prevalent in primary care.

Sexual orientation was registered in the patients' records in 34\% of the MSM cases. Information about the patient origins in HIV endemic countries was registered for $56 \%$ of the patients from the migrant group.

The list of IC is too long and therefore not applicable in its current form in primary care.

No HIV test in $34 \%$ of the STI-related consultations in patients from high risk groups. Main reasons for not testing for HIV: patient not at risk; time of risk exposure was too recent; patient refused to be tested. 
Table 2 Studies included in the review that report on targeting patients (Continued)

\begin{tabular}{|c|c|c|c|c|}
\hline Author, year & Country & Study design & Study population & Main findings \\
\hline Joore, 2016 [47] & Netherlands & $\begin{array}{l}\text { Cross-sectional search in an } \\
\text { electronic general practice } \\
\text { database containing records } \\
\text { from } 747 \text { GPS in Rotterdam, } \\
\text { making use of a case-control } \\
\text { design, 2009-2013 }\end{array}$ & $\begin{array}{l}224 \text { HIV cases which were } \\
\text { matched with } 2193 \text { controls }\end{array}$ & $\begin{array}{l}\text { In } 32.1 \% \text { of persons } \\
\text { diagnosed with syphilis, no } \\
\text { HIV test was reported in the } \\
\text { medical records. For } \\
\text { gonorrhea this was } 44.7 \% \text {, for } \\
\text { hepatitis B } 61.5 \% \text { and for } \\
\text { chlamydia } 54.2 \% \text {. }\end{array}$ \\
\hline Menacho, 2013 [44] & Spain & $\begin{array}{l}\text { Interventional study in } 4 \\
\text { primary care centers in } \\
\text { Barcelona, 2009-2011 }\end{array}$ & $\begin{array}{l}775 \text { patients included in the } \\
\text { group with ICs and } 6604 \\
\text { patients in the group } \\
\text { without ICs }\end{array}$ & $\begin{array}{l}\text { Testing based on selected ICS } \\
\text { commonly seen in general } \\
\text { practice was feasible and } \\
\text { more efficient than non- } \\
\text { targeted HIV testing. }\end{array}$ \\
\hline Poirier, 2015 [38] & France & $\begin{array}{l}\text { Multi-center observational } \\
\text { and interventional study } \\
\text { offering rapid HIV testing, } \\
\text { 2012-2013 }\end{array}$ & $\begin{array}{l}352 \text { GPs participating in the } \\
\text { questionnaire survey and } 23 \\
\text { GPs volunteering to use rapid } \\
\text { testing }\end{array}$ & $\begin{array}{l}71 \% \text { in favour of global } \\
\text { screening of the population } \\
\text { from } 15 \text { to } 70 \text { years of age, } \\
\text { without any risk factor. }\end{array}$ \\
\hline Rayment, 2012 [39] & UK & $\begin{array}{l}\text { Multi-center cross-sectional } \\
\text { questionnaire survey } \\
\text { combined with and } \\
\text { interventional study offering } \\
\text { HIV testing, 2009-2010 }\end{array}$ & $\begin{array}{l}144 \text { primary care staff, } 1320 \\
\text { primary care patients }\end{array}$ & $\begin{array}{l}75 \% \text { of primary care staff felt } \\
\text { comfortable to provide HIV } \\
\text { testing to all patients. }\end{array}$ \\
\hline Rochetti, 2015 [35] & France & $\begin{array}{l}\text { Cross-sectional questionnaire } \\
\text { survey, } 2012\end{array}$ & 407 GPs in Paris & $\begin{array}{l}45 \% \text { of GPs were aware of } \\
\text { national HIV testing } \\
\text { recommendations; only } 8 \% \\
\text { had been trained to apply } \\
\text { these recommendations. } \\
\text { Diagnosis of a STI was } \\
\text { systematically considered as a } \\
\text { case requiring HIV screening } \\
\text { for } 80 \% \text { of the GPS. }\end{array}$ \\
\hline Thornton, 2012 [36] & UK & $\begin{array}{l}\text { Qualitative study with FGDs } \\
\text { embedded within an } \\
\text { interventional study offering } \\
\text { routine testing in non- } \\
\text { traditional settings including } \\
\text { primary care, 2009-2010 }\end{array}$ & $\begin{array}{l}6 \text { FGDs in the pre-testing } \\
\text { phase including } 10 \mathrm{GPs} ; \\
\text { FGDs in the post-testing } \\
\text { phase including } 8 \mathrm{GPs}\end{array}$ & $\begin{array}{l}\text { Routine testing was } \\
\text { perceived as a useful tool to } \\
\text { reduce HIV-related stigma. }\end{array}$ \\
\hline Trienekens, 2013 [46] & Netherlands & $\begin{array}{l}\text { Prospective observational } \\
\text { patient survey within the } \\
\text { representative Dutch sentinel } \\
\text { GP network, 2008-2011 }\end{array}$ & $\begin{array}{l}43 \text { general practices; } 2111 \\
\text { new episodes concerning } \\
\text { STI/HIV issues }\end{array}$ & $\begin{array}{l}\text { No HIV tests were carried out } \\
\text { for } 64 \% \text { of the STI-related } \\
\text { consultations involving } \\
\text { patients at higher risk for HIV. }\end{array}$ \\
\hline Vos, 2016 [31] & Belgium & $\begin{array}{l}\text { Qualitative study making use } \\
\text { of in-depth interviews, } 2011\end{array}$ & $\begin{array}{l}13 \text { GPs in urban areas in } \\
\text { Flanders }\end{array}$ & $\begin{array}{l}\text { No inclination to routinely } \\
\text { collect and register sexual } \\
\text { health information. } \\
\text { Assumptions on HIV risk } \\
\text { based on country of origin, } \\
\text { past STI episodes and sexual } \\
\text { orientation. }\end{array}$ \\
\hline
\end{tabular}

\footnotetext{
a IC Indicator condition

${ }^{\mathrm{b}} \mathrm{STI}$ sexually transmitted infection

${ }^{\mathrm{C}} \mathrm{GPs}$ general practitioners

${ }^{\mathrm{d} P W I D}$ people who inject drugs

e MSM men having sex with men

${ }^{\mathrm{f}} \mathrm{FGD}$ s focus group discussions
}

settings. In Paris, for example, GPs $(N=407)$ were pro-actively involved in HIV screening by prescribing a substantial number of tests without waiting for the patient's request [35].

A qualitative study in Flanders (Belgium) assessing HIV testing conditions showed that informed consent was often not specifically asked for. GPs believed that patients were sufficiently informed to accept or refuse the HIV test. Negative test results were communicated either by phone or during a follow up consultation. Post-test counselling was generally not provided when test results were negative. Positive test results were communicated personally, with focussed messages to alleviate the first shock after diagnosis, to give information about effective treatment and to refer to HIV care. However, some GPs did not offer any post-test 
counselling; they simply referred patients to a specialised HIV clinic [49]. In the French study among GPs $(N=$ 78 ), $69 \%$ reported that they had never communicated a diagnosis of HIV infection to their patients [37].

Regarding the type of HIV tests used, studies in both Spain $(N=1308)$ and France $(N=78)$ found that few GPs were aware of rapid testing for HIV, even among those who provided other rapid diagnostic tests $[37,50]$. Nevertheless, the use of rapid tests, both on oral fluid and finger prick blood, was received favourably. It was perceived as quick, highly acceptable to patients and as reducing the risk of patients not coming back for their test results [36-38, 50, 51]. However, many GPs did not know how to use them $[38,50]$. Potential test interpretation errors, the complexity of quality control and the significantly longer consultation time were considered as obstacles to the use of rapid tests in daily practice $[37,38,50,51]$. The immediacy of the screening result was viewed as too intrusive, both to patients and GPs [38]. Some GPs were not interested in using rapid testing due to the difficulty of screening for other STIs simultaneously [37, 50]. A longer window period compared to the latest generation laboratory test was also reported as an obstacle to the use of rapid tests [51] (see Table 3 for more information).

\section{Barriers and facilitators to HIV testing}

Concerns about the practical aspects of delivering HIV testing services emerged as an important issue. Lack of time was cited as an important operational barrier to conducting (rapid) HIV testing [36-38, 42, 48-52]. There was concern that offering an HIV test during a consultation for an apparently unrelated medical complaint might disturb the consultation process [36, 49]. While some took a pragmatic approach and understood that pre-test discussion could be brief and focussed, others believed that this was a complex and time-consuming process $[36,48-50]$.

When it came to testing migrants, language barriers and lack of culture-sensitive sexual counselling skills were reported $[49,50]$. If HIV diagnosed patients cannot have access to medical follow-up and treatment, mainly in cases of an illegal situation or forced return to their country, this appeared to be a barrier for providers who may not be willing to make people face hopeless situations [49].

Finally, GPs expressed concerns about result management, in particular about communicating test results and a potential diagnosis of HIV infection [36, 37, 49, 51]. In light of these concerns, some GPs suggested that the delivery of test results was best conducted by specialised staff, such as sexual health advisors [36]. However, some others felt encouraged to increase the offer of HIV testing when new diagnoses had been made as a result of their intervention and when these individuals had been successfully linked to HIV care $[36,49]$.

A study in the UK indicated a need for additional training to include HIV testing as a routine part of patient care [39]. This was also the case in two Belgian studies regarding provider-initiated HIV testing targeting sub-Saharan African migrants as a key-population at risk [48, 49]. GPs identified particular training needs regarding HIV epidemiology and prevention, the treatment benefits of early diagnosis and HIV management immediately after diagnosis. Some GPs requested a supportive and user-friendly tool to proactively offer HIV testing to populations at increased risk. It was felt that such a tool could support the patient-provider communication mitigating feelings of discomfort when offering and discussing the test.

A number of studies suggested that the provision of a specific training, practical tool or promotion programme had a positive effect on the testing performance of GPs [48, 53-57]. Based on the data from an observational single-centre cohort study in a UK area of high HIV prevalence, Mahendran et al. [54] suggested that the continuous supply of initiatives that support testing in primary care, such as the designation of an HIV testing advisor, simplification of the testing process and training on HIV indicator diseases, could improve the recognition and diagnosis of HIV. The study showed that there was a significant increase in the proportion of new diagnoses made within primary care from $2.7 \%$ in 2000 to $21.2 \%$ in $2012(p<0.001)$. The rate of late diagnosis decreased from 89.5 to $32.9 \%(p<0.001)$ and the diagnosis of recent infections increased from 15 to $40 \%$ $(p<0.001)$. In France, the launch in 2009 of a national guideline for HIV screening of the general population aged between 15 and 70 years, had a positive impact on the testing rates. For patients who saw their GP regularly, the intervention led to a $3.3 \%$ increase $(95 \%$ CI: $2.8-3.8$ ) in HIV testing in 2010, an $8.7 \%$ increase $(95 \%$ CI: $7.4-10.1)$ by 2011 , and a $20.4 \%$ increase $(95 \% \mathrm{CI}$ : $17.0-23.8)$ by 2013 [56].

In a high prevalence London area, a training intervention among GPs and nurses on sexual health clinical skills and sexual history taking produced a substantial increase in HIV testing rates: some surgeries increased their testing rates by more than $50 \%$ and high positivity rates $(16.7 / 1000$ tests) were achieved [55]. A cluster-randomised controlled trial in general practices in London (UK) demonstrated that a multifaceted educational programme, integrating rapid HIV testing into the registration health check, led to increased rates of HIV diagnosis with 0.30 (95\% CI: $0.11-0.85$ ) per 10,000 patients per year in intervention practices versus 0.07 (95\% CI: $0.02-0.20)$ in control practices. A high proportion of newly diagnosed patients were of Black African ethnic origin, showing successful implementation of testing in a 
Table 3 Studies included in the review that report on how the HIV test is performed

\begin{tabular}{|c|c|c|c|}
\hline Author, year & Country & Study design & Study population \\
\hline Agusti, 2013 [50] & Spain & $\begin{array}{l}\text { Cross-sectional questionnaire } \\
\text { survey, } 2012\end{array}$ & $\begin{array}{l}1308 \text { GPs }^{\text {a }} \text { from the two largest } \\
\text { Spanish scientific medical } \\
\text { societies for family and } \\
\text { community medicine }\end{array}$ \\
\hline Donker, 2013 [29] & Netherlands & $\begin{array}{l}\text { Retrospective cohort study } \\
\text { within the Dutch sentinel general } \\
\text { practice network, 1988-2009 }\end{array}$ & 56 GPs in 42 general practices \\
\hline Fraisse, 2015 [37] & France & $\begin{array}{l}\text { Cross-sectional questionnaire } \\
\text { survey, } 2013\end{array}$ & $\begin{array}{l}78 \text { GPs working in a } 150,000- \\
\text { population district in the south } \\
\text { of France }\end{array}$ \\
\hline
\end{tabular}

Gauthier, 2012 [51] France Prospective interventional study offering rapid testing in primary care, 2010

Hall, 2015 [40]

France

Cross-sectional questionnaire survey among family physicians in the Pays de la Loire, 2011-2012

Joore, $2016[42]$

Netherlands Qualitative study with FGDs and in depth-interviews, 2014

Joore, 2017 [32]

Netherlands Cross-sectional questionnaire survey among newly diagnosed HIV infected patients presenting at 2 HIV outpatient clinics in Amsterdam, 2014-2016

Loos, 2014 [48] Belgium

Manirankunda, 2012 [49] Belgium

Qualitative study making use of

in-depth interviews, 2007-2008

Qualitative evaluation making use of FGDs and in-depth interviews, 2011-2012

Poirier, 2015 [38] $\quad$ France

Multi-center observational and interventional study offering rapid HIV testing, 2012-2013

Rochetti, 2015 [35] $\quad$ France

Cross-sectional questionnaire survey, 2012

Thornton, 2012 [36] UK Qualitative study with FGDs embedded within an interventional study offering routine testing in non-traditiona settings including primary care, 2009-2010
62 GPs and 383 primary care patients, covering six French regions + 72 GPs participating in the evaluation post intervention

871 GPs

6 FGDs $^{\mathrm{b}}$ including 81 GPs and in- depth interviews with 9 key-informants

111 newly diagnosed HIV patients

65 GPs in Flanders implementing a tool to proactively offer HIV testing to Sub-Saharan African migrants

20 GPs in the cities of Ghent and Antwerp

352 GPs participating in the questionnaire survey and 23 GPs volunteering to use rapid testing

407 GPs in Paris

6 FGDs in the pre-testing phase including 10 GPs; 7 FGDs in the post-testing phase including 8 GPS
Main findings

$70 \%$ not knowing how to use a

rapid HIV test; $80 \%$ willing to use it.

For the period 1988-2009, 77 to $93 \%$ of HIV tests were based on the patient's request.

Main reasons for HIV testing were patient request (91\%) and risk of HIV infection (62\%).

$69 \%$ of GPs never communicated an HIV diagnosis.

$33 \%$ of GPs were informed about rapid HIV testing; $85 \%$ agreed with training on rapid HIV testing.

$60 \%$ of GPs were willing to use rapid tests for HIV.

HIV testing practices were mostly risk-based driven or as part of a diagnostic procedure.

GPs tend to cling to risk-based HIV testing.

In the 5 years prior to HIV diagnosis, $82.9 \%$ of the 111 patients had one or more consultations with their GP. $34.8 \%$ had one or more HIV tests performed in general practice during this period. In more than $50 \%$ of the cases the positive test was done on the request of the patient.

Suggesting an HIV test without a patient's request needs a window of opportunity such as a blood test for other medical reasons.

HIV testing was mostly patientinitiated.

No explicit informed consent was asked; no pre-test counselling; personal communication of positive test results.

$77 \%$ of GPs was in favour of using rapid testing.

$74 \%$ of GPs had prescribed up to 10 HIV tests in the previous month; $47 \%$ had prescribed the latest HIV tests without waiting for the patient's request.

Before the intervention, HIV testing practices were mostly risk-based driven or as part of a diagnostic procedure.

The use of rapid tests during the intervention phase was received favourably. 
multi-ethnic community [53] (see Table 4 for more information).

\section{Discussion}

Increasing the timely uptake of HIV testing and decreasing the number of undiagnosed people is a priority area for HIV care and prevention. International and European guidelines call vigorously for diversifying and intensifying models of HIV testing delivery within both health care and community settings [58-60]. Primary care is a frontline service providing opportunities for disease prevention, health promotion and early detection of disease. On this account it is believed that GPs have a major role to play in provider-initiated HIV testing for early case finding, which in turn may have a significant impact on the epidemic. This study is the first mixed-methods systematic review on HIV testing in general practice in Europe, summarising the available evidence on current practices and the existing barriers and facilitators to HIV testing.

This review shows that there is potential for an increased role for GPs in provider-initiated HIV testing. Available literature shows that patients usually accept being offered HIV testing in primary care, particularly when part of a general check-up or sexual health consultation [61-66]. Nevertheless, we also identified several barriers for which solutions must be identified to increase provider-initiated testing in general practice and safeguard its quality. In what is to follow, we describe the main reported barriers and propose several lines of action that could be considered to overcome these barriers.

The findings of this synthesis show that GPs are often not fully aware of the specificities of the HIV epidemic and the testing recommendations in their own countries. They request better information and training on these topics. Providing information on the HIV epidemic, notably on estimates of undiagnosed HIV prevalence and time to diagnosis by key-populations and geographical area, will be fundamental to increasing awareness and testing among GPs.

During routine GP consultations, sexual behaviours are rarely discussed and GPs feel uncomfortable with proactively offering an HIV test. HIV testing practices are mostly based on a patient's request, a reported risk or as a part of a diagnostic procedure where knowledge of HIV status is likely to have an impact on immediate clinical management. Routinely offering an HIV test for certain HIV indicator diseases, such as STIs, has been shown to be feasible and effective. However, marked variation in attitudes and practices regarding the use of the complete list of clinical HIV-indicator-diseases has been observed. Practical tools should be developed to enable GPs to identify people at high risk of HIV infection who require regular HIV testing. For example, the DENVER HIV risk score tool calculates HIV risk scores, categorising people into groups with increasing possibilities of HIV infection, which may help to prioritise HIV testing efforts [67]. The compilation of a short-list with HIV indicator diseases commonly seen in primary care could also be an interesting option. A recent study has shown that there are indeed opportunities for HIV indicator condition-guided testing in primary care [68]. As a prerequisite for using these tools, GPs should be trained to improve skills in sexual health anamnesis, intercultural competences and accurate recognition of HIV-related conditions.

The observed lack of experience in delivering test results or communicating a diagnosis of HIV infection may be a supplementary barrier to GP's readiness to offer HIV testing. The process of HIV testing must be in accordance with the international regulatory framework on provider-initiated HIV testing, comprising the World Health Organization '5Cs' principle: Consent, Confidentiality, Counselling, Correct test results and linkage to Care [59]. Importantly, pre-test counselling and informed consent procedures should be approached pragmatically without complex and time-consuming operations, while respecting confidentiality and patients' right to refuse testing. In addition, result management, including the delivery of HIV diagnoses and collaboration with specialised HIV clinics has to be adequately supported by education and training.

GPs' individual time constraints have shown to be a major barrier to routinely offering HIV testing. This will remain a difficult challenge as GPs are already overburdened with the cumulating number of tasks they must complete as primary health care providers. In consequence, the roll-out of HIV testing in primary care must take into account this reality. Next to pragmatic handling of testing procedures, evidence-based brief interventions adapted to primary care settings may be helpful [69]. They aim to develop effective communication methods, like motivational interviewing, to avoid extra time for counselling and testing.

Besides addressing the main barriers identified in this review, we believe that in order to improve 'real-world' effectiveness, testing in primary care must be an integral part of a comprehensive HIV testing strategy based on epidemiological evidence. Indeed, detailed mapping and sub-national estimates of undiagnosed HIV prevalence, of late HIV diagnosis and of HIV incidence are fundamental to identify and effectively reach-out to the most affected populations in each location. These estimates are essential to raise awareness among the public and GPs, to determine whether testing interventions increase timely HIV diagnosis and to assess their cost-effectiveness on a larger scale. A recent study produced these key estimates 
Table 4 Studies included in the review that report on barriers and facilitators

\begin{tabular}{|c|c|c|c|}
\hline Author, year & Country & Study design & Study population \\
\hline Agusti, 2013 [50] & Spain & $\begin{array}{l}\text { Cross-sectional questionnaire } \\
\text { survey, } 2012\end{array}$ & $\begin{array}{l}1308 \mathrm{GPs}^{\mathrm{a}} \text { from the two } \\
\text { largest Spanish scientific } \\
\text { medical societies for family } \\
\text { and community medicine }\end{array}$ \\
\hline Fraisse, 2015 [37] & France & $\begin{array}{l}\text { Cross-sectional questionnaire } \\
\text { survey, } 2013\end{array}$ & $\begin{array}{l}78 \text { GPs working in a } 150,000- \\
\text { population district in the } \\
\text { south of France }\end{array}$ \\
\hline Gauthier, 2012 [51] & France & $\begin{array}{l}\text { Prospective interventional } \\
\text { study offering rapid testing in } \\
\text { primary care, } 2010\end{array}$ & $\begin{array}{l}62 \text { GPs and } 383 \text { primary care } \\
\text { patients, covering six French } \\
\text { regions }+72 \text { GPs } \\
\text { participating in the } \\
\text { evaluation post intervention }\end{array}$ \\
\hline Gennotte, 2013 [52] & Belgium & $\begin{array}{l}\text { Prospective interventional } \\
\text { study offering rapid HIV } \\
\text { testing in a Brussels area with } \\
\text { a substantial African } \\
\text { community, 2010-2011 }\end{array}$ & $\begin{array}{l}10 \text { GPs and } 1087 \text { consultation } \\
\text { records, } 217 \text { primary care } \\
\text { patients offered rapid HIV } \\
\text { testing }\end{array}$ \\
\hline Joore, 2016 [42] & Netherlands & $\begin{array}{l}\text { Qualitative study with FGDs } \\
\text { and in depth-interviews, } 2014\end{array}$ & $\begin{array}{l}6 \text { FGDs including } 81 \text { GPs and } \\
\text { in- depth interviews with } 9 \\
\text { key-informants }\end{array}$ \\
\hline Leber, 2015 [53] & UK & $\begin{array}{l}\text { Cluster randomised } \\
\text { controlled trial among } \\
\text { general practices in a multi- } \\
\text { ethnic, socioeconomically } \\
\text { deprived inner London } \\
\text { borough, 2010-2011. } \\
\text { Practices were randomised to } \\
\text { offer either opt-out rapid } \\
\text { testing to newly registering } \\
\text { adults or continue usual care. }\end{array}$ & $\begin{array}{l}20 \text { general practices in the } \\
\text { intervention group and } 20 \text { in } \\
\text { the control group }\end{array}$ \\
\hline Loos, 2014 [48] & Belgium & $\begin{array}{l}\text { Qualitative evaluation making } \\
\text { use of focus group } \\
\text { discussions and in-depth in- } \\
\text { terviews, 2011-2012 }\end{array}$ & $\begin{array}{l}65 \text { GPs implementing a tool } \\
\text { to proactively offer HIV } \\
\text { testing to Sub-Saharan } \\
\text { African migrants }\end{array}$ \\
\hline
\end{tabular}

Mahendran, 2015 [54] UK A single-center observational cohort study in an outpatient HIV department in a secondary care UK hospital assessing the site of initial HIV diagnosis and stage of infection, 2000-2012

Manirankunda, 2012 [49] Belgium Qualitative study making use of in-depth interviews, 2007-2008
Main findings

Barriers to provide (rapid) HIV

testing: lack of time; lack of training; cultural barriers.

Barriers to provide rapid HIV testing: time constraints.

Barriers to provide rapid HIV testing: difficulties to perform the test; lack of time; window period; difficulties to screen for other STIs.

Barriers to provide (rapid) HIV testing: lack of time; difficulties to propose the test

Barriers to provide HIV testing: difficulties in targeting the right group; lack of time; fear of stigmatizing patients.

HIV diagnosis rate was 0.30 [95\%Cl: $0.11-0.85$ ] per 10,000 patients per year in intervention practices versus 0.07 [95\%Cl: 0.02-0.20] in control practices.

Barriers to provide HIV testing: feelings of discomfort to offer the test, lack of counselling skills and time constraints.

GPs identified training needs on the specificities of the HIV epidemic

GPs requested a tool to proactively offer HIV testing to populations at increased risk improved the testing performance.

1359 diagnosed HIV patients

Increase in the proportion of HIV diagnoses made in primary care: from $2.7 \%$ in 2000 to $21.2 \%$ in 2012. Decrease in the proportion of late diagnoses from $89.5 \%$ in 2000 to $42 \%$ in 2012.

20 GPs in the cities of Ghent and Antwerp
Barriers to provide HIV testing: time constraints, concerns about result management, concerns about lack of access to treatment for migrants in an illegal situation. 
Table 4 Studies included in the review that report on barriers and facilitators (Continued)

\begin{tabular}{|c|c|c|c|c|}
\hline Author, year & Country & Study design & Study population & Main findings \\
\hline Pilay, 2014 [55] & UK & $\begin{array}{l}\text { An interventional study } \\
\text { consisting of a training in } \\
\text { sexual health skills in a high } \\
\text { HIV prevalence London area, } \\
2010-2011\end{array}$ & 51 general practice settings & $\begin{array}{l}\text { Testing rates of trained and } \\
\text { untrained practices increased } \\
\text { from } 2.29 \text { to } 6.66 \text { and } 1.54 \text { to } \\
1.90 / 1000 \text { registered patients/ } \\
\text { year. } \\
16.7 \text { positive diagnoses per } \\
1000 \text { tests in trained } \\
\text { practices, corresponding to a } \\
\text { rise from } 9.5 \text { to } 22 \text { new } \\
\text { diagnoses per year. }\end{array}$ \\
\hline Poirier, 2015 [38] & France & $\begin{array}{l}\text { Multi-center observational } \\
\text { and interventional study } \\
\text { offering rapid HIV testing, } \\
\text { 2012-2013 }\end{array}$ & $\begin{array}{l}352 \text { GPs participating in the } \\
\text { questionnaire survey and } 23 \\
\text { GPs volunteering to use rapid } \\
\text { testing }\end{array}$ & $\begin{array}{l}\text { Barriers to provide rapid HIV } \\
\text { testing: difficulties to include } \\
\text { preventive screening in GP } \\
\text { consultation; low prevalence; } \\
\text { immediacy of test results in } \\
\text { case of rapid testing. }\end{array}$ \\
\hline Rayment, 2012 [39] & UK & $\begin{array}{l}\text { Multi-center cross-sectional } \\
\text { questionnaire survey com- } \\
\text { bined with and interventional } \\
\text { study offering HIV testing, } \\
\text { 2009-2010 }\end{array}$ & $\begin{array}{l}144 \text { primary care staff, } 1320 \\
\text { primary care patients }\end{array}$ & $\begin{array}{l}72 \% \text { of GPs identified a need } \\
\text { for training to include HIV } \\
\text { testing as a routine part of } \\
\text { patient care. }\end{array}$ \\
\hline Sicsic, 2016 [56] & France & $\begin{array}{l}\text { Retrospective observational } \\
\text { study making use of data } \\
\text { from the French National } \\
\text { health Insurance Fund } \\
\text { database, 2006-2013 }\end{array}$ & $\begin{array}{l}2.176,647 \text { person-years corre- } \\
\text { sponding to } 329.748 \text { different } \\
\text { individuals aged between } 15 \\
\text { and } 70\end{array}$ & $\begin{array}{l}\text { Annual HIV screening rates } \\
\text { increased from } 4.2 \% \text { [ } 95 \% \mathrm{Cl} \text { : } \\
4.2-4.3] \text { in } 2006 \text { to } 5.8 \% \text { [95\% } \\
\text { Cl: } 5.7-5.9 \text { ] in } 2013 \text { with a } \\
\text { significant trend after } 2010 \\
(p<0.0001) \text {. The increase was } \\
\text { stronger for those that } \\
\text { regularly consulted a GP: the } \\
\text { national screening policy led } \\
\text { to a } 20.4 \% \text { increase } 95 \% \mathrm{Cl} \text { : } \\
17 \%-23.8] \text { in } 2013 \text { compared } \\
\text { to a } 4.5 \% \text { increase [95\% Cl: } \\
4.4-4.5] \text { for those who did } \\
\text { not consult a GP regularly in } \\
2013 .\end{array}$ \\
\hline Thornton, 2012 [36] & UK & $\begin{array}{l}\text { Qualitative study with FGDs } \\
\text { embedded within an } \\
\text { interventional study offering } \\
\text { routine testing in non- } \\
\text { traditional settings including } \\
\text { primary care, 2009-2010 }\end{array}$ & $\begin{array}{l}6 \text { FGDs in the pre-testing } \\
\text { phase including } 10 \mathrm{GPs} ; 7 \\
\text { FGDs in the post-testing } \\
\text { phase including } 8 \mathrm{GPs}\end{array}$ & $\begin{array}{l}\text { Barriers to provide HIV } \\
\text { testing: lack of time; concerns } \\
\text { about results management. } \\
\text { Routine offer to HIV testing in } \\
\text { general practice is feasible } \\
\text { but requires training and } \\
\text { support for staff. }\end{array}$ \\
\hline Tong, 2012 [57] & UK & $\begin{array}{l}\text { Prospective interventional } \\
\text { study adding a standard } \\
\text { comment to encourage } \\
\text { inclusion of HIV testing to all } \\
\text { Glandular fever screening } \\
\text { reports, } 2010-2011\end{array}$ & $\begin{array}{l}871 \text { glandular fever screening } \\
\text { samples from } 865 \text { patients } \\
\text { submitted from primary care }\end{array}$ & $\begin{array}{l}\text { After the introduction of the } \\
\text { standard comment, } 19.6 \% \\
\text { had a concomitant HIV } \\
\text { request as compared to } 9.5 \% \\
\text { in the baseline period. }\end{array}$ \\
\hline
\end{tabular}

\footnotetext{
${ }^{\mathrm{a}} G$ s general practitioners
}

${ }^{\mathrm{b}}$ FGDs focus group discussions

at a granular level in France using detailed national HIV surveillance data [70]. However, they remain to be produced at national and sub-national level in most settings.

Finally, HIV testing programs should be integrated within a balanced combination prevention framework, including biomedical, behavioural and structural interventions that address the complex interplay of underlying determinants of HIV transmission. All this requires equal access to a continuum of HIV prevention, testing and care services for all without discrimination, and implemented through a multi-sectorial and participatory approach [66, 71].

There are some limitations to our review. Studies were only included if they had been published as research articles in English-language peer-reviewed journals. Relevant data from grey literature or publications in other languages were therefore excluded from this review. Another limitation derives from the sparse literature available, making a cross-European comparison impossible. One third of the retrieved studies were 
performed in the UK, a limited number were conducted in alternate Western-European countries, but none originated from other European regions. This may be partially explained by the national differences in health care delivery models and screening organisation. We also acknowledge that some of the implementation and evaluation studies included in this review were operating under ideal circumstances, and the positive results obtained may not be achievable in the real life conditions of busy primary care practices.

\section{Conclusions}

This review provides evidence of the conditions under which GPs could play an increased role in provider-initiated HIV-testing for early case finding, which is essential to improve health outcomes and to reduce transmission risks. It will be necessary to further elaborate on the identified solutions to reported barriers and to define specific testing criteria adapted to primary healthcare. This process should be conducted in collaboration with relevant stakeholders such as GPs, patient organisations and policy makers. Since it is a complex task to incorporate changes into clinical practice [72], further studies will be needed to promote and evaluate HIV testing in primary care, including its impact, effectiveness, quality and associated costs.

\section{Additional files}

Additional file 1: Reported Items of the PRISMA checklist. (PDF $29 \mathrm{~kb}$ )

Additional file 2: Sample search strategy in PubMed. (PDF $22 \mathrm{~kb}$ )

Additional file 3: Quality assessment tool. (PDF $51 \mathrm{~kb}$ )

\section{Abbreviations}

CD4: Cluster of Differentiation 4; EEA: European Economic Area; EU: European Union; GP: General Practitioner; HIV: Human Immunodeficiency Virus; MSM: Men having sex with men; STI: Sexually Transmitted Infection

\section{Acknowledgements \\ We gratefully acknowledge the members of the HERMETIC Study Group: Hanne Apers (ITM, Belgium), Jessika Deblonde (Sciensano, Belgium), Anda Kivivite (RSU, Latvia), Jasna Loos (ITM, Belgium), Lise Marty (INSERM U1136, France), Christiana Nöstlinger (ITM, Belgium), Daniela Rojas Castro (AIDES, France), Virginie Supervie (INSERM U1136, France), Dominique Van Beckhoven (Sciensano, Belgium) \\ We acknowledge Chloé Wyndham Thomas (Sciensano, Belgium) for the language revision.}

\section{Funding}

This work was supported by IWT (Belgium) and the ANRS (France) through the framework of HIVERA JTC 2014

\section{Availability of data and materials}

The datasets generated and analysed during the current study are included in this published article (Tables 1, 2, 3 and 4). Additional files are provided: Additional file 1: Reported Items of the PRISMA checklist; Additional file 2: Sample search strategy in PubMed; Additional file 3: Quality assessment tool. Supplementary information files are available from the corresponding author on reasonable request.

\section{Authors' contributions}

JD developed the concept of the manuscript. JD and DVB screened and selected the studies to be included in the review. CN and JD adapted the checklist to be used for quality appraisal. JD carried out the analysis and wrote the first draft. NB contributed to the analysis and interpretation of the data as concerns HIV testing during STI consultations. JL contributed to the analysis and interpretation of the data, in particular with regard to HIV testing of migrants and the need for training for general practitioners. AS contributed to the analysis and interpretation of the data in terms of understanding HIV testing in the perspective of clinical practice and the broader epidemiological context. DVB, JL, NB and AS contributed to the writing of the paper. CN and VS contributed equally to the supervision of the writing process. $\mathrm{CN}$ ensured the embedment of the combination prevention approach and she also addressed the link between research results and changing clinical practices. VS provided the framing with the HIV incidence data and the estimates of undiagnosed HIV prevalence. All coauthors read and critically revised the subsequent drafts of the manuscript, approved the final version and agreed to be accountable for all aspects of the work.

Ethics approval and consent to participate

Not applicable.

\section{Consent for publication}

Not applicable.

\section{Competing interests}

The authors declare that they have no competing interests.

\section{Publisher's Note}

Springer Nature remains neutral with regard to jurisdictional claims in published maps and institutional affiliations.

\section{Author details}

'Sciensano, Epidemiology of Infectious Diseases, Juliette Wytsmanstraat 14, 1050 Brussels, Belgium. ${ }^{2}$ Sciensano, Health Services Research, Juliette Wytsmanstraat 14, 1050 Brussels, Belgium. ${ }^{3}$ Department of Public Health, Institute of Tropical Medicine, Nationalestraat 155, 2000 Antwerp, Belgium. ${ }^{4}$ Faculty of Psychology, University of Vienna, Vienna, Austria. ${ }^{5}$ Institut Pierre Louis d'Epidémiologie et de Santé Publique, INSERM, Sorbonne Université, 56 Bd. Vincent Auriol, CS 81393, 75646 Paris Cedex 13, France.

Received: 19 February 2018 Accepted: 10 October 2018 Published online: 22 October 2018

References

1. Cohen MS, Chen YQ, McCauley M, Gamble T, Hosseinipour MC, Kumarasamy $\mathrm{N}$, et al. Antiretroviral therapy for the prevention of HIV-1 transmission. N Engl J Med. 2016;375(9):830-9.

2. INSIGHTSTARTStudyGroup. Initiation of antiretroviral therapy in early asymptomatic HIV infection. N Engl J Med. 2015;373(9):795-807.

3. Rodger A, Bruun T, Weait M, Vernazza P, Collins S, Estrada V, et al. Partners of people on ART - a new evaluation of the risks (the PARTNER study): design and methods. BMC Public Health. 2012;12:296.

4. Deblonde J, De Koker P, Hamers FF, Fontaine J, Luchters S, Temmerman M. Barriers to HIV testing in Europe: a systematic review. Eur J Public Health. 2010:20(4):422-32.

5. Mocroft A, Lundgren JD, Sabin ML, Monforte AD, Brockmeyer N, Casabona J, et al. Risk Factors and Outcomes for Late Presentation for HIV-Positive Persons in Europe: Results from the Collaboration of Observational HIV Epidemiological Research Europe Study (COHERE). PLoS Med. 2013;10(9):e1001510.

6. Mocroft A, The Late Presenters Working Group in COHERE in EuroCoord. Late presentation for HIV care accross Europe: update from the Collaboration of Observational HIV Epidemiological Research Europe (COHERE) study, 2010-2013. Eurosurveillance. 2015;20:47.

7. Supervie V, Ndawinz JDA, Lodi S, Costagliola D. The undiagnosed HIV epidemic in France and its implications for HIV screening strategies. AIDS. 2014;28:12. 
8. Skarbinski J, Rosenberg E, Paz-Bailey G. Human immunodeficiency virus transmission at each step of the care continuum in the United States. JAMA Intern Med. 2015;175(4):588-96.

9. van Sighem A, Pharris A, Quinten C, Noori T, Amato-Gauci A, the ECDC HIV/ AIDS Surveillance and Dublin Declaration Monitoring Networks. Reduction in undiagnosed HIV infection in the European Union/European Economic Area, 2012 to 2016. Eurosurveillance. 2017;22:48.

10. UNAIDS. 90-90-90 An ambitious treatment to target to help end the AIDS epidemic. Available at: http://www.unaids.org/sites/default/files/media_ asset/90-90-90 en 0.pdf. Geneva; 2014.

11. Boffin N, Moreels S, Deblonde J, Van Casteren V. Four sexually transmitted infections (STIS) in Belgian general practice: first results (2013-2014) of a nationwide continuing surveillance study. BMJ Open. 2017;7(1):e012118. https://doi.org/10.1136/bmjopen-2016-012118

12. Kall MM, Smith RD, Delpech VC. Late HIV diagnosis in Europe: a call for increased testing and awareness among general practitioners. Eur J Gen Pract. 2012;18(3):181-6.

13. Leber W, Anderson J, Griffiths C. HIV testing in Europe: how can primary care contribute? Sex Transm Infect. 2015;91(7):464-5.

14. Ma R. Time to improve HIV testing and recording of HIV diagnosis in UK primary care. Sex Transm Infect. 2009;85(7):486.

15. van Bergen JEAM. Commentary on: late HIV diagnoses in Europe: a call for increased testing and awareness among general practitioners. Eur J Gen Pract. 2012;18(3):133-5

16. Lee $K$, Wright $S M$, Wolfe $L$. The clinically excellent primary care physician: examples from the published literature. BMC Fam Pract. 2016;17(1):169.

17. Burns FM, Johnson AM, Nazroo J, Ainsworth J, Anderson J, Fakoya A, et al. Missed opportunities for earlier HIV diagnosis within primary and secondary healthcare settings in the UK. AIDS. 2008;22(1):115-22.

18. Champenois K, Cousien A, Cuzin L, Sp LV, Deuffic-Burban S, Lanoy E, et al. Missed opportunities for HIV testing in newly-HIV-diagnosed patients, a cross sectional study. BMC Infect Dis. 2013;13:200.

19. Sandelowski M, Voils Cl, Barroso J. Defining and designing mixed research synthesis studies. Res Sch. 2006;13(1):29.

20. Heyvaert M, Maes B, Onghena P. Mixed methods research synthesis definition, framework, and potential. Qual Quant. 2013;47:2. https://doi.org/ 10.1007/s11135-011-9538-6.

21. Moher D, Liberati A, Tetzlaff J, Altman DG. Preferred reporting items for systematic reviews and meta-analyses: the PRISMA statement. BMJ. 2009;21:339.

22. Centers for Disease Control and Prevention US. Revised recommendations for HIV testing of adults adoloscents and pregnant women in health care settings. Available at: https://www.cdc.gov/mmwr/preview/mmwrhtml/ rr5514a1.htm. Morbidity and Mortality Weekly Report 2006;55 (RR-14):1-17.

23. Expert panel on effective ways of investing in health (EXPH). Definition of a frame of reference in relation to primary care with a special emphasis on financing systems and referral systems. Available at: https://ec.europa.eu/ health/expert_panel/sites/expertpanel/files/004_definitionprimarycare_en. pdf. Brussels: EXPH; 2014

24. ECDC. Migrant health: sexual transmission of HIV within migrant groups in the EU/EEA and implications for effective interventions. Available at: https:// ecdc.europa.eu/sites/portal/files/media/en/publications/Publications/ Migrant-health-sexual-transmission.pdf. Stockholm: European Centre for Disease Prevention and Control; 2013.

25. Fakoya I, Alvarez-del Arco D, Woode-Owusu M, Monge S, RiveroMontesdeoca $Y$, Delpech $V$, et al. A systematic review of post-migration acquisition of HIV among migrants from countries with generalised HIV epidemics living in Europe: implications for effectively managing HIV prevention programmes and policy. BMC Public Health. 2015;15(1):561

26. NICE. Methods for the development of NICE public health guidance. Available at: https://www.ncbi.n/m.nih.gov/pubmedhealth/PMH0089896/ pdf/PubMedHealth_PMH0089896.pdf. London: National Institute for Health and Care Excellence; 2012

27. Carter SM, Ritchie JE, Sainsbury P. Doing good qualitative research in public health: not as easy as it looks. NSW Public Health Bull. 2009;20(8):105-11.

28. Evans HER, Mercer CH, Rait G, Hamill M, Delpech V, Hughes G, et al. Trends in HIV testing and recording of HIV status in the UK primary care setting: a retrospective cohort study 1995-2005. Sex Transm Infect. 2009;85(7):520-6.

29. Donker G, Dorsman S, Spreeuwenberg P, van den Broek I, van Bergen J. Twenty-two years of HIV-related consultations in Dutch general practice: a dynamic cohort study. BMJ Open. 2013;3(4):e001834. https://doi.org/10. 1136/bmjopen-2012-001834.
30. Sadler KE, Low N, Mercer CH, Sutcliffe LJ, Islam MA, Shafi S, et al. Testing for sexually transmitted infections in general practice: cross-sectional study. BMC Public Health. 2010;10:667.

31. Vos J, Pype P, Deblonde J, Van den Eynde S, Aelbrecht K, Deveugele M, et al. Collecting and registering sexual health information in the context of HIV risk in th eelectronic medical record of general practitioners: a qualitative exploration of the preference of general practitioners in urban communities in Flandres (Belgium). Prim Health Care Res Dev. 2016;17(4):333-50.

32. Joore IK, Geerlings SE, Brinkman K, van Bergen JEAM, Prins JM. The importance of registration of sexual orientation and recognition of indicator conditions for an adequate HIV risk-assessment. BMC Infect Dis. 2017;17(1):178.

33. British HIV Association, British Association of Sexual Health and HIV, British Infection Society. UK national guidelines for HIV testing. Available at: https://www.bhiva.org/file/RHNUJglseDaML/ GlinesHIVTest05.pdf. London; 2008.

34. Hindocha S, Charlton T, Rayment M, Theobald N. Feasibility and acceptability of routine human immunodeficiency virus testing in general practice: your views. Primary Health Care Res Dev. 2013;14:212-6.

35. Rocchetti $V$, Viard JP. Family practitioners screening for HIV infection. Med Mal Infect. 2015;45(5):157-64.

36. Thornton AC, Rayment M, Elam G, Atkins M, Jones R, Nardone A, et al. Exploring staff attitudes to routine HIV testing in non-traditional settings: a qualitative study in four healthcare facilities. Sex Transm Infect. 2012;88(8):601-6.

37. Fraisse T, Fourcade C, Brazes-Sanz J, Koumar Y, Lavigne JP, Sotto A, et al. A cross sectional survey of the barriers for implementing rapid HIV testing among French general practitioners. Int J STD AIDS. 2016;27(11):1005-12.

38. Poirier C, Aymeric S, Grammatico-Guillon L, Lebeau JP, Bernard L, Le Bret P, et al. Rapid HIV test in family practice. Med Mal Infect. 2015;45(6):207-14.

39. Rayment M, Thornton A, Mandalia S, Elam G, Atkins M, Jones R, et al. HIV testing in non-traditional settings the HINTS study: a multi-Centre observational study of feasibility and acceptability. PLoS One. 2012;7(6):e39530.

40. Hall N, Crochette N, Blanchi S, Lavoix A, Billaud E, Baron C, et al. Family physicians and HIV infection. Med Mal Infect. 2015;45(11):456-62.

41. HIV in Europe. HIV indicator conditions: guidance for implementing HIV testing in adults in health care settings. Available at: hiveurope.eu/Portals/0/ Guidance.pdf.pdf. Copenhagen; 2012.

42. Joore IK, van Roosmalen SL, van Bergen JE, van Dijk N. General practitioners barriers and facilitators towards new provider-initiated HIV testing strategies: a qualitative study. Int J STD AIDS. 2016;28(5):459-66.

43. Agusti C, Montoliu A, Mascort J, Carrillo R, Almeda J, Elorza JM, et al. Missed opportunities for HIV testing of patients diagnosed with an indicator condition in primary care in Catalonia, Spain. Sex Transm Infect. 2016;92(5):387-92.

44. Menacho I, Sequeira E, Muns M, Barba O, Leal L, Clusa T, et al. Comparison of two HIV testing strategies in primary care centres: indicator-conditionguided testing vs. testing of those with non-indicator conditions. HIV Med. 2013;14:33-7.

45. Joore IK, Reukers DFM, Donker GA, van Sighem Al, de Coul ELM O, Prins JM, et al. Missed opportunities to offer HIV tests to high-risk groups during general practitioners STI-related consultations: an observational study. BMJ Open. 2016;6(1):e009194. https://doi.org/10. 1136/bmjopen-2015-009194.

46. Trienekens SCM, van den Broek IVF, Donker GA, van Bergen JEAM, van der Sande MAB. Consultations for sexually transmitted infections in the general practice in the Netherlands: an opportunity to improve STI/HIV testing. BMJ Open. 2013:3(12):e003687.

47. Joore IK, Twisk DE, Vanrolleghem AM, de Ridder M, Geerlings SE, van Bergen JEAM, et al. The need to scale up HIV indicator conditionguided testing for early case-finding: a case-control study in primary care. BMC Fam Pract. 2016;17(1):161. https://doi.org/10.1186/s12875016-0556-2.

48. Loos J, Manirankunda L, Hendrickx K, Remmen R, Noestlinger C. HIV testing in primary care: feasibility and acceptability of provider initiated HIV testing and counseling for sub-Saharan African migrants. AIDS Educ Prev. 2014;26(1):81-93.

49. Manirankunda L, Loos J, Debackaere P, Noestlinger C. It is not easy: challenges for provider-initiated HIV testing and counseling in Flanders, Belguim. AIDS Educ Prev. 2012;24(5):456-68. 
50. Agusti C, Fernández-Lopez L, Mascort J, Carrillo R, Aguado C, Montoliu A, et al. Acceptability of rapid HIV diagnosis technology among primary healthcare practitioners in Spain. AIDS Care. 2013;25(5):544-9.

51. Gauthier R, Livrozet JM, Prevoteau du Clary F, Taulera O, Bouee S, Aubert JP, et al. Feasibility and acceptability of rapid HIV test screening (DEPIVIH) by French family physicians. Med Mal Infect. 2012;42(11):553-60.

52. Gennotte AF, Semaille P, Ellis C, Necsoi C, Abdulatif M, Chellum N, et al. Feasibility and acceptability of HIV screening through the use of rapid tests by general practitioners in a Brussels area with a substantial African community. HIV Med. 2013;14:57-60.

53. Leber W, McMullen H, Anderson J, Marlin N, Santos AC, Bremner S, et al. Promotion of rapid testing for HIV in primary care (RHIVA2): a clusterrandomised controlled trial. Lancet HIV. 2015;2(6):e229-35.

54. Mahendran P, Soni S, Goubet S, Saunsbury E, Roberts J, Fisher M. Testing initiatives increase rates of HIV diagnosis in primary care and community settings: an observational single-Centre cohort study. PLoS One. 2015;10(4): e0124394.

55. Pillay TD, Mullineux J, Smith CJ, Matthews P. Unlocking the potential: longitudinal audit finds multifaceted education for general practice increases HIV testing and diagnosis. Postgrad Med J. 2014; 90(1060):86-91.

56. Sicsic J, Saint-Lary O, Rouveix E, Pelletier-Fleury N. Impact of a primary care national policy on HIV screening in France: a longitudinal analysis between 2006 and 2013. Br J Gen Pract. 2016;66(653):e920.

57. Tong CYW, O'Shea S, Palmer S, Peck J, Ruf M. Is the addition of a standard HIV educational comment to virology laboratory reports effective in changing requesting behaviour? J Clin Virol. 2012;53(1):85-7.

58. ECDC. Guidance HIV testing: increasing uptake and effectiveness in the European Union. Available at: https://ecdc.europa.eu/sites/portal/files/ media/en/publications/Publications/101129_GUI_HIV_testing.pdf. Stockholm: European Centre for Disease Prevention and Control; 2010

59. WHO. Consolidated guidelines on HIV testing services. Available at: http:// apps.who.int/iris/bitstream/10665/179870/1/9789241508926_eng.pdf?ua= 1\&ua=1. Geneva: World Health Organisation; 2015.

60. WHOEurope. Scaling up HIV testing and counselling in the WHO European Region. A policy framework. Available at: http://www.euro.who.int/_data/ assets/pdf_file/0007/85489/E93715.pdf. Copenhagen: World Health Organisation Regional Office Europe; 2010.

61. Drayton R, Keane F, Prentice E. Patients' attitudes towards increasing the offer of HIV testing in primary and secondary care. Int J STD AIDS. 2010;21(8):563-6.

62. Glew S, Pollard A, Hughes L, Llewellyn C. Public attitudes towards opt-out testing for HIV in primary care: a qualitative study. Br J Gen Pract. 2014; 64(619):e60-6

63. O'Kelly M, Byrne D, Naughten E, Bergin C, Williams C. Opt-out testing for blood-borne viruses in primary care: a multicentre, prospective study. Br J Gen Pract. 2016;66(647):e392-6.

64. Pollard A, Llewellyn C, Smith H, Richardson D, Fisher M. Opt-out testing for HIV: perspectives from a high prevalence community in south-East England, UK. Int J STD AIDS. 2013;24(4):307-12.

65. Prost A, Griffiths CJ, Anderson J, Wight D, Hart GJ. Feasibility and acceptability of offering rapid HIV tests to patients registering with primary care in London (UK): a pilot study. Sex Transm Infect. 2009; 85(5):326-9

66. Navaza B, Abarca B, Bisoffi F, Pool R, Roura M. Provider-initiated HIV testing for migrants in Spain: a qualitative study with health care workers and foreign-born sexual minorities. PLoS One. 2016;11(2):e0150223.

67. Haukoos JS, Lyons MS, Lindsell CJ, Hopkins E, Bender B, Rothman RE, et al. Derivation and validation of the Denver human immunodeficiency virus (HIV) risk score for targeted HIV screening. Am J Epidemiol. 2012;175(8):838-46.

68. Joore IK, Arts DL, Kruijer MJ, Moll van Charante EP, Geerlings SE, Prins JM, et al. HIV indicator condition-guided testing to reduce the number of undiagnosed patients and prevent late presentation in a high-prevalence area: a case-control study in primary care. Sex Transm Infect. 2015;91(7):467-72.

69. Resnicow K, Dilorio C, Soet JE, Borrelli B, Hecht J, Ernst D. Motivational interviewing in health promotion: it sounds like something is changing Health Psychol. 2002;21(5):444-51.

70. Marty L, Cazein F, Panjo H, Pillonel J, Costagliola D, Supervie V and the HERMETIC Study Group. Revealing Geographical and Population
Heterogeneity in HIV Incidence, Undiagnosed HIV Prevalence and Time to Diagnosis to Improve Prevention and Care: Estimates for France. J Int AIDS Soc. 2018;21:e25100.

71. Deblonde J, Sasse A, del Amo J, Burns F, Delpech V, Cowan S, et al. Restricted access to antiretroviral treatment for undocumented migrants: a bottle neck to control the HIV epidemic in the EU/EEA. BMC Public Health. 2015;15(1):1228

72. Kristensen N, Nymann C, Konradsen H. Implementing research results in clinical practice - the experiences of healthcare professionals. BMC Health Serv Res. 2016;16(1):48

\section{Ready to submit your research? Choose BMC and benefit from:}

- fast, convenient online submission

- thorough peer review by experienced researchers in your field

- rapid publication on acceptance

- support for research data, including large and complex data types

- gold Open Access which fosters wider collaboration and increased citations

- maximum visibility for your research: over $100 \mathrm{M}$ website views per year

At BMC, research is always in progress.

Learn more biomedcentral.com/submissions 